\title{
Total solids content: a key parameter of metabolic pathways in dry anaerobic digestion
}

\author{
Jean-Charles Motte, Eric Trably, Renaud Escudié, Jérôme Hamelin, Jean-Philippe Steyer, Nicolas Bernet, \\ Jean-Philippe Delgenes and Claire Dumas*
}

\begin{abstract}
Background: In solid-state anaerobic digestion (AD) bioprocesses, hydrolytic and acidogenic microbial metabolisms have not yet been clarified. Since these stages are particularly important for the establishment of the biological reaction, better knowledge could optimize the process performances by process parameters adjustment.

Results: This study demonstrated the effect of total solids (TS) content on microbial fermentation of wheat straw with six different TS contents ranging from wet to dry conditions (10 to 33\% TS). Three groups of metabolic behaviors were distinguished based on wheat straw conversion rates with 2,200, 1,600, and 1,400 mmol.kgvs ${ }^{-1}$ of fermentative products under wet (10 and 14\% TS), dry (19 to 28\% TS), and highly dry (28 to 33\% TS) conditions, respectively. Furthermore, both wet and dry fermentations showed acetic and butyric acid metabolisms, whereas a mainly butyric acid metabolism occurred in highly dry fermentation.

Conclusion: Substrate conversion was reduced with no changes of the metabolic pathways until a clear limit at $28 \%$ TS content, which corresponded to the threshold value of free water content of wheat straw. This study suggested that metabolic pathways present a limit of TS content for high-solid AD.
\end{abstract}

Keywords: Biohydrogen, Dark fermentation, Fermentative metabolites, Moisture content, Lignocellulosic residues

\section{Background}

At present, anaerobic digestion (AD) of agricultural waste such as manure and lignocellulosic residues represents an economical, environmental, and societal opportunity to produce massively renewable energy (methane and hydrogen) and agricultural amendment through a digestate of high agronomic quality $[1,2]$. The $\mathrm{AD}$ process is supported by complex microbial ecosystems capable of converting the organic matter into methane and carbon dioxide by the following four steps: hydrolysis, acidogenesis, acetogenesis, and methanogenesis. Nowadays, AD bioprocess systems are mature technologies, with constant development since the 1990s [3]. Process design is mostly dependent on the waste characteristics which constrain the temperature (mesophilic or thermophilic), the configuration (one- or two-stage reactors), or the feeding modes (mono-substrate or codigestion) [3,4]. Water content is known to be one of the most important parameters that can affect the whole

\footnotetext{
* Correspondence: claire.dumas@supagro.inra.fr
INRA, UR0050, Laboratoire de Biotechnologie de I'Environnement, Avenue

* Correspondence: claire.dumas@supagro.inra.fr
INRA, UR0050, Laboratoire de Biotechnologie de I'Environnement, Avenue des Etangs, Narbonne F-11100, France
}

(C) 2013 Motte et al.; licensee BioMed Central Ltd. This is an open access article distributed under the terms of the Creative Commons Attribution License (http://creativecommons.org/licenses/by/2.0), which permits unrestricted use, distribution, and reproduction in any medium, provided the original work is properly cited. process of $\mathrm{AD}[1,5,6]$. Therefore, total solids (TS) content processes: wet digestion for TS $<15 \%$ and dry digestion or high-solid TS $>15$ to $20 \%[1,3]$. Operating AD under dry conditions offers the advantage of reducing reactor size, liquid/solid separation systems, and lowering energy consumption for bioprocess heating $[7,8]$.

Intrinsic advantages of dry $\mathrm{AD}$ bioprocesses have led to an early industrial development of digesters operated between 20 and 30\% TS and up to 40\% TS for some technologies [7]. However, this technical development was mainly based on empirical knowledge. Among the few studies dealing with the effect of TS content, Brown et al. [9] showed significant differences in anaerobic kinetics between wet and dry digestion, but no impact on methane yields. The effect of TS content on AD was also reported by Abbassi-Guendouz et al. [8] with cardboard and by Staley et al. [10] with residential area waste. Both studies reported a similar strong inhibition of AD performances for TS higher than $30 \%$ with a failure in methane production through the accumulation of volatile fatty acids (VFAs). The solid-state conditions favored the 
emergence of specific microorganisms [11]. AbbassiGuendouz et al. [12] observed the emergence of specific fermenting species of Clostridium in inhibited systems at high TS content. So far, the effect of TS content on dry microbial fermentation has rarely been evaluated. Only two studies compared the effects of a gradient of TS content (from 21 to $35 \%$ TS [13] and from 10 to $35 \%$ TS [14]) on biohydrogen production. Both concluded to a decrease of hydrogen production with an increase of TS content and the importance of alkalinity to buffer the media. However, these studies did not evaluate the impact of TS content on the metabolic pathways involved in dry conditions. Therefore, there is an important lack of knowledge on microbial fermentation metabolism related to the water content reduction.

The first two steps of AD, hydrolysis and acidogenesis, are commonly considered as the limiting steps of solid waste degradation $[4,10,15]$. During these steps, several fermentative microbial pathways can be involved to degrade the organic matter [13]. Microbial fermentation consists in waste degradation to simple molecules that will be further used as substrate by methanogenic consortia [16]. As shown in Table 1, three categories of fermentative endproducts are generated when methanogenesis is blocked or inhibited: 1) a gaseous phase composed of hydrogen and carbon dioxide; 2) by-products associated with hydrogenproducing pathways, that is acetic and butyric acid; and 3) other metabolites of non-hydrogen-generating pathways such as propionic, valeric, and caproic acids, ethanol, or lactic acid [16,17]. Since acetic and butyric acids are easier to degrade than other VFAs or organic acids $[16,18]$, their production and distribution after acidogenesis can be very informative on the ability of the system to easily start-up. A butyric/acetic acid molar ratio of 1.5 is often considered as an indicator of good operation of the microbial fermentation process [16]. Since hydrogen and its by-products, acetic and butyric acid, are easier to degrade, promoting their corresponding pathways could result in an improvement of methanogenesis kinetics [19]. Consequently, the accumulation of nonhydrogen metabolites could lead to methanogenesis inhibition, and conditions favoring AD inhibition should be avoided [20]. The feasibility of treating wheat straw, which is a model of lignocellulosic residues, in dry AD technology was previously demonstrated $[9,21]$. The objective of this study is to investigate the impact of TS content on microbial fermentation pathways of wheat straw, from wet to dry conditions.

\section{Results and discussion}

Effect of total solids (TS) content on acidogenesis microbial activity

\section{Lignocellulose characterization}

Wheat straw had an initial TS content of $95.6 \pm 0.7 \%$ and a volatile solids (VS) content of $88.9 \pm 0.7 \%$. Wheat straw fiber analysis indicated the following fractionation (based on TS content): $9.4 \pm 0.6 \%$ of soluble fraction, $33.0 \pm 1.1 \%$ of hemicellulose, $43.7 \pm 1.3 \%$ of cellulose, and $6.4 \pm 0.8 \%$ of lignin. According to drying test results, the critical water content of the straw $\mathrm{w}_{\mathrm{c}}$ was estimated at $2.4 \pm 0.2 \mathrm{g.g}_{\mathrm{TS}}{ }^{-1}$, which corresponds to a critical TS content of $29.4 \pm 1.6 \% \mathrm{g.g}^{-1}$ [24]. Production of gaseous compounds was monitored throughout the fermentation process in the reactors operated at six different TS contents. In all conditions, production of hydrogen and carbon dioxide ended after 11 days of operation.

\section{Production of gaseous compounds}

Production of gaseous compounds globally decreased with the increase of TS content from more than $35 \mathrm{NmL} \mathrm{g}_{\mathrm{TS}}{ }^{-1}$

Table 1 Main balance reactions presented in anaerobic microbial fermentation

\begin{tabular}{|c|c|c|c|c|}
\hline Metabolic pathway & $\begin{array}{l}\text { Equation } \\
\text { number }\end{array}$ & Type of fermentation & Reaction & Informative products \\
\hline Hydrogen-producing & 1 & Glucose fermentation & $\mathrm{C}_{6} \mathrm{H}_{12} \mathrm{O}_{6}+2 \mathrm{H}_{2} \mathrm{O} \rightarrow 2 \mathrm{CH}_{3} \mathrm{COOH}+2 \mathrm{CO}_{2}+4 \mathrm{H}_{2}$ & Acetic acid, hydrogen \\
\hline Hydrogen-producing & 2 & Glucose fermentation & $\mathrm{C}_{6} \mathrm{H}_{12} \mathrm{O}_{6} \rightarrow \mathrm{CH}_{3} \mathrm{CH}_{2} \mathrm{CH}_{2} \mathrm{COOH}+2 \mathrm{CO}_{2}+2 \mathrm{H}_{2}$ & Butyric acid, hydrogen \\
\hline Hydrogen-producing & 3 & Propionic acid fermentation & $\begin{array}{l}\mathrm{CH}_{3} \mathrm{CH}_{2} \mathrm{COOH}+\mathrm{H}_{2} \mathrm{O} \rightarrow \mathrm{CH}_{3} \mathrm{COOH}+\mathrm{CO}_{2}+ \\
\mathrm{H}_{2} \mathrm{O}+\mathrm{H}_{2}\end{array}$ & Acetic acid, hydrogen \\
\hline Hydrogen-consuming & 4 & Homoacetogenesis & $2 \mathrm{CO}_{2}+4 \mathrm{H}_{2} \rightarrow \mathrm{CH}_{3} \mathrm{COOH}+2 \mathrm{H}_{2} \mathrm{O}$ & Acetic acid \\
\hline Hydrogen-consuming & 5 & Propionic acid production & $\mathrm{C}_{6} \mathrm{H}_{12} \mathrm{O}_{6}+\mathrm{H}_{2} \rightarrow 2 \mathrm{CH}_{3} \mathrm{CH}_{2} \mathrm{COOH}+2 \mathrm{H}_{2} \mathrm{O}$ & Propionic acid \\
\hline Other metabolism & 6 & $\begin{array}{l}\text { Propionic acid and ethanol } \\
\text { consumption }\end{array}$ & $\begin{array}{l}\mathrm{CH}_{3} \mathrm{CH}_{2} \mathrm{OH}+\mathrm{CH}_{3} \mathrm{CH}_{2} \mathrm{COOH} \rightarrow \\
\mathrm{CH}_{3} \mathrm{CH}_{2} \mathrm{CH}_{2} \mathrm{CH}_{2} \mathrm{COOH}+\mathrm{H}_{2} \mathrm{O}\end{array}$ & Valeric acid \\
\hline Other metabolism & 7 & $\begin{array}{l}\text { Butyric acid and ethanol } \\
\text { consumption }\end{array}$ & $\begin{array}{l}\mathrm{CH}_{3} \mathrm{CH}_{2} \mathrm{OH}+\mathrm{CH}_{3} \mathrm{CH}_{2} \mathrm{CH}_{2} \mathrm{COOH} \rightarrow \\
\mathrm{CH}_{3} \mathrm{CH}_{2} \mathrm{CH}_{2} \mathrm{CH}_{2} \mathrm{CH}_{2} \mathrm{COOH}+\mathrm{H}_{2} \mathrm{O}\end{array}$ & Caproic acid \\
\hline Other metabolism & 8 & Glucose fermentation & $\mathrm{C}_{6} \mathrm{H}_{12} \mathrm{O}_{6} \rightarrow 2 \mathrm{CH}_{3} \mathrm{CH}_{2} \mathrm{OH}+2 \mathrm{CO}_{2}$ & Ethanol \\
\hline Other metabolism & 9 & Glucose fermentation & $\mathrm{C}_{6} \mathrm{H}_{12} \mathrm{O}_{6} \rightarrow 2 \mathrm{CH}_{3} \mathrm{CHOHCOOH}+2 \mathrm{CO}_{2}$ & Lactic acid \\
\hline
\end{tabular}

Hydrogen-producing, hydrogen-consuming, and other metabolites are produced during acidogenesis and reveal the use of the substrate. For a more efficient methanogenesis, hydrogen-producing pathways should be favored. Adapted from Guo et al. [16], Valdez-Vazquez and Poggi-Varaldo [17], Cord-Ruwisch et al. [22], and Stadtman et al. [23]. 
for 10 and 14\% TS, between 22 and 26 NmL.g Ts $^{-1}$ from 19 to $28 \%$ TS, and less than $20 \mathrm{NmL} \cdot \mathrm{gTS}^{-1}$ for 28 and $30 \%$ TS. Based on kinetics and production of gaseous compounds, two distinct behaviors within the four replicates were observed at $28 \%$ TS: two replicates (named 28a\% TS) had a similar trend to the experiments carried out at lower TS values, while two other replicates (named $28 \mathrm{~b} \%$ TS) behaved as at higher TS content. Other indicators are presented in Figure 1 to differentiate the conditions: the time to achieve $90 \%$ of the total hydrogen and carbon dioxide production, the hydrogen content (ratio $\mathrm{H}_{2}$ /gaseous products), and the biohydrogen yield. The time to achieve $90 \%$ of the hydrogen production was affected by the TS content: it was less than 4 days between $10 \%$ and $28 \mathrm{a} \%$ TS (fast reaction rate), and more than 8 days between $28 \mathrm{~b} \%$ and $33 \%$ TS (slow reaction rate). Moreover, the hydrogen content was strongly impacted and significantly decreased with the increase of TS content, from about $55 \%$ of hydrogen at $10 \%$ TS to $15 \%$ at $33 \%$ TS. Hydrogen production was lowered by the increase of TS content and three groups were distinguished $(P$ value of $2.8 \mathrm{e}-13,<0.001)$ : at 10 and $14 \% \mathrm{TS}$, hydrogen production was higher than $15 \mathrm{NmL} . \mathrm{g}_{\mathrm{TS}}{ }^{-1}$, between 8 and 9 NmL.g TS $^{-1}$ at 19 to $28 \%$ TS, and lower than 5 NmL.g ${ }_{\mathrm{TS}}{ }^{-1}$ at 28 and 33\% TS. Based on the correlation of Monlau et al. [25], the soluble sugar analysis indicated a hydrogen potential of $21.6 \mathrm{NmL} \cdot \mathrm{g}_{\mathrm{TS}}{ }^{-1}$. The hydrogen potential of the wheat straw estimate was higher than the 17.8 NmL.g ${ }_{\text {TS }}^{-1}$ of hydrogen obtained at $10 \%$ TS. Even though the hydrogen potential is higher than generally

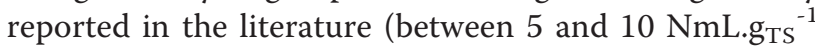

$[26,27])$, the results suggest that only the soluble phase of the substrate was degraded.

\section{Conversion into metabolites}

In addition to production of gaseous products, soluble fermentative end-products were simultaneously produced. Total concentration of soluble metabolites increased with the increase in TS content, with $3.6 \pm 0.2,5.4 \pm 0.3,5.6 \pm$ $0.5,6.4 \pm 1.0,8.0 \pm 0.4,9.8 \pm 1.2$, and $11.9 \pm 1.4$ g.L ${ }^{-1}$ of soluble phase at $10,14,19,24,28 \mathrm{a}, 28 \mathrm{~b}$, and $33 \% \mathrm{TS}$, respectively. The decrease of water content leads to high apparent metabolite concentrations. These concentrations are theoretically highly inhibitory for methanogenic activity, even though they are classically observed with no inhibition in dry $\mathrm{AD}$ [1]. The overall final $\mathrm{pH}$ remained constant around $5.5 \pm 0.1$ for all conditions despite the high concentration of soluble products. This $\mathrm{pH}$ was within the range of optimal $\mathrm{pH}$ for dark fermentation (between 5 and 6) [16,28], because of the presence of the MES buffer. Therefore, in this experiment, the absence of inhibition due to the potential acidification of the medium was likely due to the presence of a buffer. In Figure 2, the molar concentration of end-products $\left(\mathrm{H}_{2}, \mathrm{CO}_{2}, \mathrm{VFA}\right.$, ethanol, and lactate) was normalized by the amount of TS in the medium. The corresponding data are presented in Additional file 1. The sum of all these products, after normalization, indicates the reaction advancement of the microbial conversion of wheat straw. According to the TS content, three groups were distinguished based on substrate conversion advancement ( $P$ value of $5.7 \mathrm{e}-12,<0.001)$ : 10 and $14 \%$ TS with approximately $2,288 \pm 168 \mathrm{mmol} \mathrm{kg}_{\mathrm{TS}}{ }^{-1}$

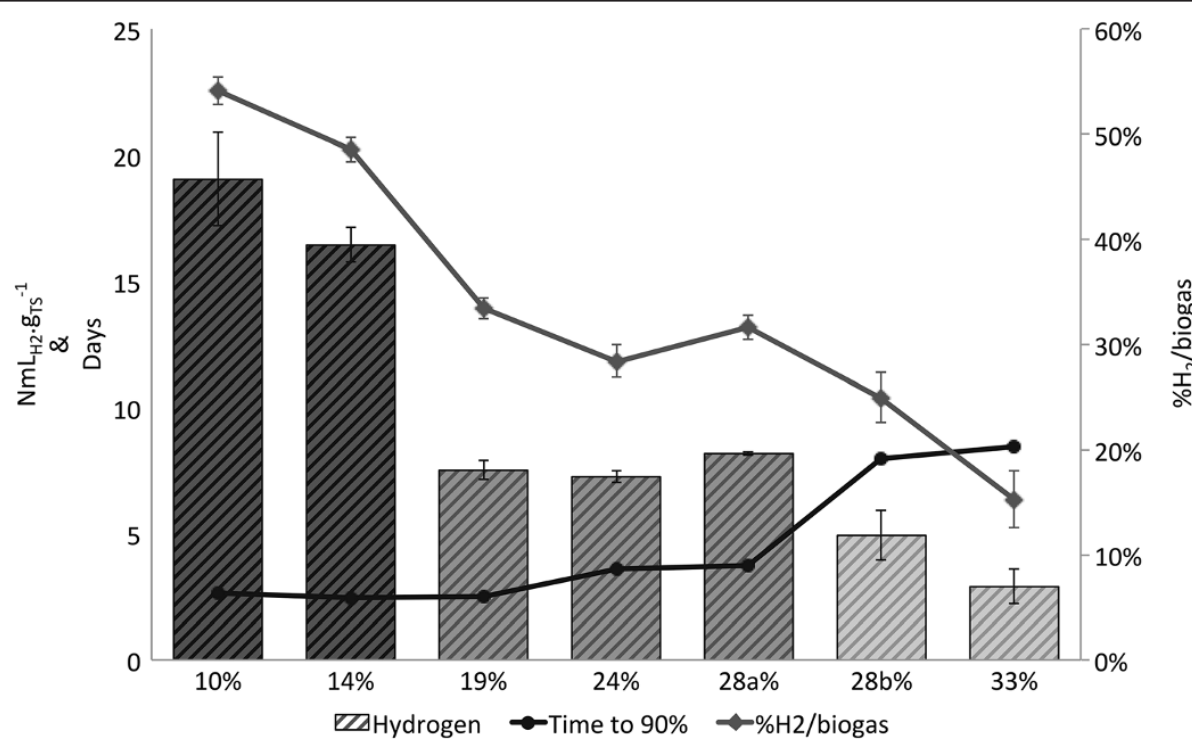

Figure 1 Biohydrogen production for the six TS contents tested. Results are expressed in terms of maximal volume, percentage of hydrogen produced, and time to achieve $90 \%$ of the total hydrogen production. These fermentation performances distinguished three groups of TS content. TS, total solids. 


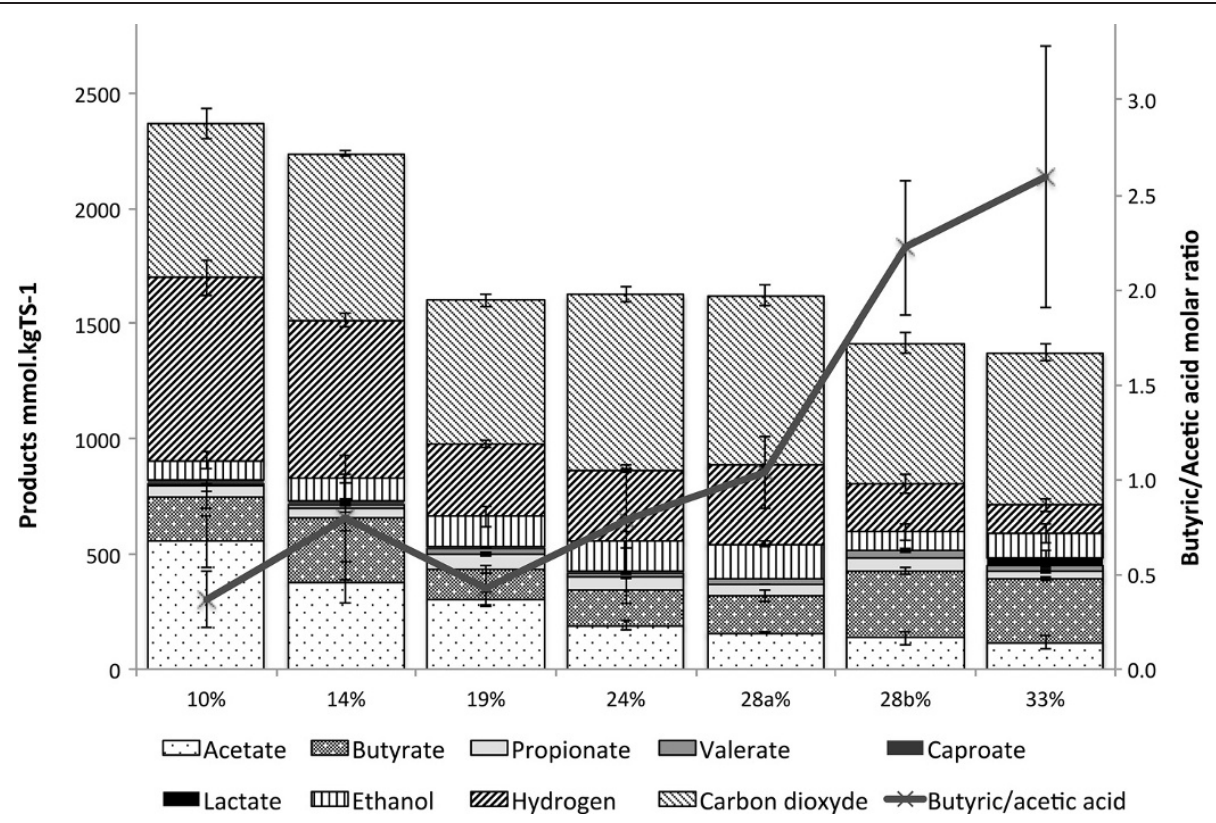

Figure 2 Distribution of fermentative products and butyric/acetic acid ratio for the six TS contents tested. These metabolites were measured after 11 days of reaction, expressed in mole unit, and reported on the initial TS content of the straw. The sum of fermentative products indicates the straw conversion yield. The butyric/acetic acid ratio indicated a metabolic shift that occurred at 28\% TS. TS, total solids.

of fermentative products, 19 to $28 \mathrm{a} \%$ TS with approximately 1,610 $\pm 41 \mathrm{mmol} \cdot \mathrm{kg}_{\mathrm{TS}}{ }^{-1}$, and finally $28 \mathrm{~b}$ and $33 \% \mathrm{TS}$ with approximately $1,389 \pm 38$ mmol. $\mathrm{kg}_{\mathrm{TS}}{ }^{-1}$.

Table 2 shows the distribution of metabolites regarding the three following categories: gaseous products, soluble products associated with hydrogen production (acetic and butyric acid), and soluble products leading to no hydrogen production (other VFAs, ethanol, and lactate). For all the conditions, the proportion of gaseous products $\left(\mathrm{H}_{2}\right.$ and $\left.\mathrm{CO}_{2}\right)$ was in the same order of magnitude, between 57 and $67 \%$ of the sum of metabolites. However, as revealed by the hydrogen/carbon dioxide ratio, three groups were distinguished ( $P$ value of $2.1 \mathrm{e}-11,<0.001)$ : 10 and $14 \%$ TS with a hydrogen/carbon dioxide molar ratio of $1.06 \pm 0.14,19$ to $28 \mathrm{a} \%$ TS with $0.46 \pm 0.05$, and $28 \mathrm{~b}$ to $33 \%$ TS with $0.23 \pm 0.09$. On the overall range of TS content, the hydrogen associated VFAs, that is acetic and butyric acids, represented between 20 and $32 \%$ of the sum of

Table 2 Distribution of fermentative products for the six conditions

\begin{tabular}{|c|c|c|c|c|c|c|}
\hline Categories & Unit (molar \%) & Wet (W) & Dry (D) & Highly dry (HD) & Similarity & Similarity \\
\hline & & $10 \% \leq \mathrm{TS} \leq 14 \%$ & $19 \%<$ TS $<28 \%$ & $28 \%<$ TS $\leq 33 \%$ & W-D group & W-D group \\
\hline Gas products & Total products & $63 \% \pm 2$ & $63 \% \pm 5$ & $57 \% \pm 5$ & Similar $(P=0.34, \mathrm{~ns})$ & Different $\left(P=1 \mathrm{e}-2^{*}\right)$ \\
\hline Hydrogen & \multirow[t]{2}{*}{ Gas products } & $51 \% \pm 3$ & $31 \% \pm 3$ & $18 \% \pm 6$ & Different $\left(P=3 \mathrm{e}-7^{* * *}\right)$ & Different $\left(P=2 \mathrm{e}-4^{* * *}\right)$ \\
\hline Carbon dioxide & & $49 \% \pm 3$ & $69 \% \pm 3$ & $82 \% \pm 6$ & Different $\left(P=3 e-7^{* * *}\right)$ & Different $\left(P=2 \mathrm{e}-4^{* * *}\right)$ \\
\hline $\begin{array}{l}\text { Hydrogen associated } \\
\text { with VFAs }\end{array}$ & Total products & $30 \% \pm 3$ & $23 \% \pm 5$ & $29 \% \pm 2$ & Different $\left(P=3 e-2^{*}\right)$ & Different $\left(P=2 \mathrm{e}-4^{* * *}\right)$ \\
\hline Acetic acid & \multirow{2}{*}{$\begin{array}{l}\text { Hydrogen associated } \\
\text { with VFAs }\end{array}$} & $62 \% \pm 12$ & $62 \% \pm 10$ & $29 \% \pm 5$ & Similar $(P=0.12, \mathrm{~ns})$ & Different $\left(P=5 \mathrm{e}-7^{* * *}\right)$ \\
\hline Butyric acid & & $38 \% \pm 10$ & $38 \% \pm 12$ & $71 \% \pm 5$ & Similar $(P=0.12, \mathrm{~ns})$ & Different $\left(P=5 \mathrm{e}-7^{* * *}\right)$ \\
\hline Other metabolites & Total products & $7 \% \pm 2$ & $14 \% \pm 2$ & $13 \% \pm 4$ & Different $\left(P=3 e-5^{* * *}\right)$ & Similar $(P=0.26, \mathrm{~ns})$ \\
\hline Propionic acid & Concurrent metabolite & $23 \% \pm 4$ & $26 \% \pm 3$ & $26 \% \pm 13$ & Similar $(P=0.54, \mathrm{~ns})$ & Similar $(P=0.39, \mathrm{~ns})$ \\
\hline Valeric acid & & $7 \% \pm 3$ & $12 \% \pm 3$ & $14 \% \pm 3$ & Different $\left(P=7 \mathrm{e}-4^{*}\right)$ & Different $\left(P=2 \mathrm{e}-2^{*}\right)$ \\
\hline Caproic acid & & $15 \% \pm 7$ & $1 \% \pm 2$ & $0 \% \pm 0$ & Different $\left(P=2 \mathrm{e}-7^{* * *}\right)$ & Similar $(P=0.07, \mathrm{~ns})$ \\
\hline Lactic acid & & $0 \% \pm 0$ & $0 \% \pm 0$ & $12 \% \pm 13$ & Similar $(P=0.27, \mathrm{~ns})$ & Different $\left(P=2 \mathrm{e}-3^{*}\right)$ \\
\hline Ethanol & & $55 \% \pm 7$ & $60 \% \pm 7$ & $52 \% \pm 10$ & Similar $(P=0.71, \mathrm{~ns})$ & Similar $(P=0.12, \mathrm{~ns})$ \\
\hline
\end{tabular}

The three groups of TS contents are classified in three categories: gaseous products, VFAs associated with the production of hydrogen, and other metabolites. The similarity between group wet and dry and group dry and highly dry is indicated based on ANOVA. $P$ value levels of significance: ${ }^{*}<0.05 ;{ }^{* *}<0.01 ; * * *<0.001 ;$ and $\mathrm{ns},>0.05$. D, dry; HD, highly dry; ns, not significant; TS, total solids; VFA, volatile fatty acid; W, wet. 
metabolites. However, their distribution revealed only two groups based on the butyric/acetic acid molar ratios ( $P$ value of $2.6 \mathrm{e}-8,<0.001$ ): from 10 to $28 \mathrm{a} \%$ TS with an average value of $0.69 \pm 0.32$, and $28 \mathrm{~b}$ and $33 \%$ TS with a significantly higher ratio of $2.47 \pm 0.59$. Homoacetogenic activity was quantified by estimating a theoretical molar balance between the hydrogen produced or consumed for the production of acetic, propionic, and butyric acids from the glucose equivalent and the experimental amount of hydrogen (equation 1, 2, and 5). The difference indicated the hydrogen consumed, mainly by homoacetogenesis: $462,312,357,174,81,303$, and 359 mmol. $\mathrm{kg}_{\mathrm{TS}}{ }^{-1}$ of missing hydrogen at $10,14,19,24,28 \mathrm{a}, 28 \mathrm{~b}$, and $33 \% \mathrm{TS}$, respectively. If for every condition the molar balance was in agreement with the accumulation of acetic acid, at $28 \mathrm{~b}$ and $33 \%$ TS a lack of hydrogen was observed that could not be explained by any metabolite production. The other fermentative products (propionic, valeric, and caproic acids, ethanol, and lactate) are associated with no hydrogen-producing pathways and corresponded to less than $7 \%$ of the total fermentative products for 10 and $14 \%$ TS, and more than $13 \%$ from 19 to $33 \%$ TS. The product distribution within this category was similar in most of the operating conditions for ethanol $(P$ value of 0.17 , not significant) and propionic acids ( $P$ value of 0.45 , not significant) corresponding to $25 \pm 7 \%$ and $56 \pm 8 \%$ of the other metabolites, respectively. The main differences of the 'no hydrogen' metabolism were the measurement of $17 \%$ of lactate at $33 \%$ TS $(P$ value of $2 \mathrm{e}-3,<0.05)$ and approximately $15 \%$ of caproic acid at 10 and $14 \%$ TS ( $P$ value of $2 \mathrm{e}-7,<0.001$ ), and a decrease of valeric acid quantity at 10 and $14 \%$ TS ( $P$ value of $7 \mathrm{e}-4,<0.05)$.

\section{Distinguishment of three acidogenesis behaviors}

In this study, the increase in TS contents had two consecutive consequences on acidogenesis: a sharp reduction of $25 \%$ in wheat straw conversion between 14 and $19 \%$ TS, followed by a clear shift in metabolite distribution at $28 \%$ TS. A microbial community analysis was performed on the final media to verify the origin of the metabolite distribution. Additional file 2 shows these results in more detail. The absence of correlation between the profile and TS content could attribute the butyric acid production to a metabolic shift and not to the emergence of a new population. Based on these observations, a classification in three groups of the effect of TS content on acidogenesis is proposed: a wet fermentation group (W) for $10 \% \leq \mathrm{TS} \leq 14 \%$, a dry fermentation group (D) for $19 \% \leq \mathrm{TS}<28 \mathrm{a} \%$, and a highly dry fermentation group (HD) for $28 \mathrm{~b} \%<\mathrm{TS} \leq 33 \%$.

\section{Wet fermentation group (W)}

The group W, that is 10 and $14 \%$ TS batch tests, corresponds to water-saturated conditions usually described as wet digestion for $\mathrm{AD}$ systems. Wet digestion is characterized by a liquid medium, which allows homogeneity in the bioreactor, full access of the degrading microorganisms to the substrate, and dilution of inhibitory products (VFAs) [15]. Under these conditions, the substrate conversion rate is mainly limited by solid hydrolysis [29]. Concerning the fermentation, group $\mathrm{W}$ is characterized by the highest hydrogen production (more than 15 NmL. $\mathrm{g}_{\mathrm{TS}}{ }^{-1}$ ), a fast reaction, and a hydrogen-producing pathway-oriented metabolism (more than $50 \%$ of the gaseous products). Fermentative end-products corresponded mainly to hydrogen and carbon dioxide (approximately $63 \%$ of the total metabolites), acetic and butyric acids (approximately $30 \%$ of the total metabolites), and ethanol and propionic acids (for the last $7 \%$ ). Additionally, butyric/ acetic acid ratios of 0.4 and 0.8 , observed respectively at 10 and $14 \%$ TS, are low when compared to the overall stoichiometric ratio of 1.5 for hydrogen production reported by Guo et al. [16]. These low ratios resulted from higher production of acetic acid. Since the fermentation was achieved in 4 days, which resulted in a decrease of hydrogen concentrations in headspace, this acetic acid production was probably associated with hydrogen consumption. Therefore, hydrogen-consuming pathways were likely to occur either through homoacetogenesis (low butyric/acetic acid ratio, equation 4) or the propionic acidproducing pathway (equation 5) [17]. Overall, the group W shows a microbial metabolism favorable to the synthesis of microbial by-products that are easily degradable by subsequent methanogenesis (hydrogen, acetic acid, and butyric acid) $[19,20]$.

\section{Dry fermentation group (D)}

In group $\mathrm{D}$, that is batch tests operated between 19 and $28 \mathrm{a} \%$ TS, metabolite distribution and reaction rate were both similar to group W. The distribution of soluble fermentative products corresponded mainly to acetic and butyric acids (23\% of total metabolites), with a butyric/ acetic acid ratio ranging from 0.4 to 1.0 . These ratios are consistent with literature data for dark fermentation under dry conditions [30]. Here again, such metabolite distribution resulted from the delay between metabolite analysis and fermentation achievement (4 days). The decrease of hydrogen content in gas phase and an increase of carbon dioxide production were also observed in group D. Both observations, hydrogen consumption and low butyric/acetic acid ratio, suggested a significant homoacetogenesis. The homoacetogenic activity was of a lower proportion than in group W experiments: $17 \% \pm 4$ of the total straw conversion against $8 \% \pm 4$. Therefore, the decrease of hydrogen content can be explained by higher production of concurrent metabolites (30\% more), which conducts to a direct consumption of hydrogen to generate propionic acid (equation 5) or the production of carbon dioxide and ethanol with no hydrogen (equation 8). 
Therefore, both ethanol and propionic acid can explain the decrease of the hydrogen/gaseous product ratio. Microorganisms involved in the production of ethanol and propionic acid are known to be more resistant to environmental stress than hydrogen-producing bacteria [18,31]. The decrease of substrate conversion yield of $30 \%$ between groups W and D (1,300 down to 900 mmol. $\mathrm{kg}_{\mathrm{TS}}{ }^{-1}$ of fermentative product) was likely caused by the decrease of substrate accessibility due to the reduction of water content. Indeed, switching from wet to dry conditions makes it more difficult for microorganisms to access solids [32]. This hypothesis is also consistent with the slight changes of metabolisms observed between groups $\mathrm{W}$ and $\mathrm{D}$, and the decrease of performances generally observed in dry digestion processes [6]. The limit between the two groups occurred between 14 and 19\% TS in this study and is consistent with literature data, although this limit has not been clearly defined with values varying between 15 and $20 \%$ TS $[3,8,9]$. In the present study, no clear threshold value could be determined and further studies are required by refining the TS content between 14 and 19\% TS.

\section{Highly dry fermentation group (HD)}

Group HD, that is 28b and 33\% TS batch tests, was characterized by very low hydrogen production, low hydrogen/gaseous product ratio, and slow fermentation rates requiring 8 days to reach the maximum hydrogen productivity. The substrate conversion was reduced by approximately $40 \%$ of group W and $15 \%$ of group D. Thus, by reducing the water content, its effect was increased in group HD, with a slight increase in ethanol and propionic acid production. This observation could partly explain the reduction of hydrogen content in gas phase (only 18\%) by a higher production of carbon dioxide. If the amount of acetic acid is similar to group D, a very high concentration of butyric acid was measured [26]. Since every mole of butyric acid produced is associated with the production of two moles of hydrogen (equation 2), the quantity of hydrogen measured is lower than expected $\left(288 \mathrm{mmol}^{\mathrm{kg}} \mathrm{kg}^{-1}\right.$ of butyric acid against 163 mmol. $\mathrm{kg}_{\mathrm{Ts}}{ }^{-1}$ of hydrogen). Although the existence of hydrogen-consuming pathways that could have redirected microbial activity (equation 4 and 5), the low quantity of acetic and propionic acids fails to explain the occurrence of high concentration of butyric acid concomitant to a low hydrogen yield. These observations may suggest a butyric pathway with no hydrogen production $[8,10]$. Such a pathway is rarely described in the literature and results from a complex chain of reactions. For example, a rare pathway constituting of acetic acid and glucose consumption to produce butyric acid was observed in acidified thermophilic condition [33]. The important decrease of water according to the increase of TS content could explain such a metabolic shift occurring under these very particular conditions by an effect on the medium acidity.

In addition, the value of $28 \%$ TS corresponded to a critical TS content. Two duplicates (28a\%) behaved like experiments in group D (19 and 24\% TS), while the two others $(28 \mathrm{~b} \%)$ were classified in group HD. Interestingly, similar shifts were previously reported and discussed in studies dealing with organic solids AD $[8,10]$. Even though the tested substrate differs (cardboard versus urban waste), these experimental works identified a threshold value of approximately $30 \%$ TS, beyond that AD was inhibited by high VFA accumulation. Abbassi-Guendouz et al. [12] found the emergence of specific bacterial communities for highly dry AD (Clostridium) and specific Archaea for groups W, D, and HD. To explain this phenomenon, Staley et al. [10] suggested that the role of local spatial heterogeneities is essential, as proposed elsewhere by Martin [32]. These authors assumed that the reduction in water content could create high local concentrations of inhibitory products leading to depleted zones with no microbial activity. However, such niches were not observed at a centimeter scale [10]. It was proposed that these depleted areas could exist but at microscopic scale [32]. Based on experimental and modeling approaches, a similar threshold of $30 \%$ TS was observed with two distinct behaviors where semi-liquid and dry conditions (10 to $30 \%$ TS) were limited by microbial hydrolysis rates, and highly dry digestion (30 and 35\% TS) was limited by liquid/gas mass transfers [8]. According to drying test results, the critical TS content was estimated at 29.4 \pm 1.6\% (ratio in $\mathrm{g}_{\mathrm{TS}} \mathrm{g}^{-1}$ ). Therefore, at higher TS contents, no free water was available for wheat straw degradation. Interestingly, the limit between the dry and highly dry group [8] is consistent with the critical TS content shown in this study with two different substrates and batch reactors operated under different conditions, for example no $\mathrm{pH}$ buffering. This value may be the limit above which free water appears to be limiting in the medium. The highly dry fermentation might be affected by a lack of free water available for microbial activity with consequences in microbial metabolisms, as shown in this study. In solid-state fermentation, Orzua et al. [24] suggested that the free water content is an important parameter impacting both biological and physical mechanisms of the system [15,32]. Since the lack of free water appeared only for TS content higher than $29 \%$, extracellular enzymatic activity might remain active [34]. Further studies are required to verify whether this critical TS content may correspond to the maximum TS content to be applied for efficient acidogenesis on organic waste.

\section{Conclusions}

The present study investigates the effect of TS content on wheat straw acidogenesis from wet to highly dry conditions (10 to 33\% TS) (Figure 3). Compared to wet 


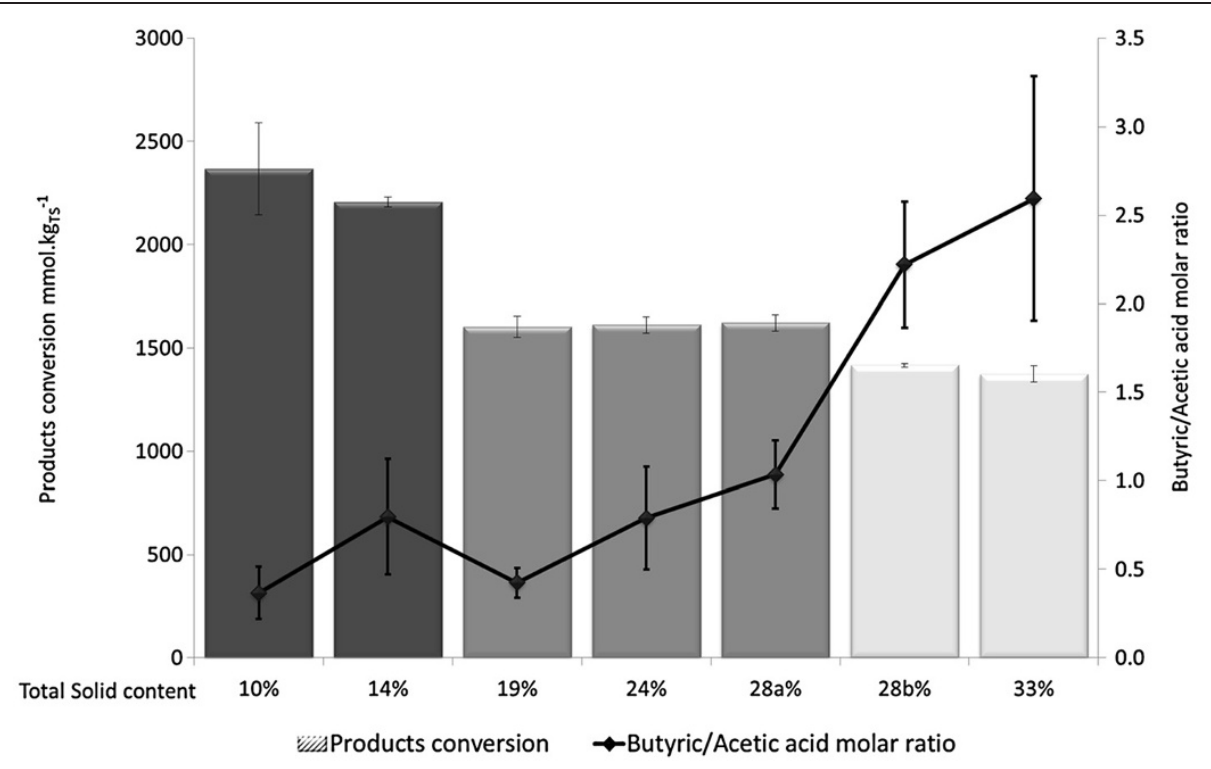

Figure 3 Summary illustration of the observations of the experiment. The product conversion corresponds to the sum of metabolites and gaseous products, which indicated the substrate conversion. If a reduction of substrate conversion occurred when TS content increased, a metabolic shift was only identified at $28 \%$ TS. TS, total solids.

conditions, dry media faced heterogeneities responsible for a decrease of substrate conversion yield without modification of the metabolic pathways. However, a metabolism shift unfavorable for hydrogen production was observed at $28 \%$ TS. It was supposed that this clear limit is linked to the decrease of free water in the media. This work concludes that fermentation of lignocellulosic waste in dry conditions could be optimized in order to produce hydrogen or valuable VFAs.

\section{Methods}

\section{Substrate}

Wheat straw (Triticum aestivum) was harvested in July 2010 at an organic farm located in the Hérault region of France. A bale was homogenized manually, aliquoted in plastic bags, and stored at ambient temperature. The straw was then milled at $1 \mathrm{~mm}$ and sieved between 0.4 and 1 $\mathrm{mm}$. The Van Soest fractionation was performed with the fiberbag system (Gerhardt, Crailsheim, Germany). The proportion of free and bound water was assessed with a drying test of wheat straw, according to the protocol proposed by García-Bernet et al. [35]. This method identifies the moisture content when the water evaporation kinetic starts to decrease. This point, marking the transition between bound to free water, is defined as the critical water fraction $\mathrm{w}_{\mathrm{c}}$ (water content expressed in $\left.\mathrm{g} \cdot \mathrm{g}_{\mathrm{TS}}{ }^{-1}\right)$.

\section{Inoculum source}

Four different digestates were sampled in AD plants treating organic waste to obtain a high microbial diversity in the initial anaerobic inoculum. A mix of inocula was prepared to equalize the contribution of each inoculum source ( $25 \%$ in VS basis). Two digestates were collected from two upflow anaerobic sludge blanket (UASB) digesters treating effluents from a sugar factory or sludge from a wastewater treatment plant under mesophilic and thermophilic conditions, respectively. Two other digestates were sampled in two dry anaerobic digesters treating the organic fraction of municipal waste and operated under mesophilic and thermophilic conditions. The digestates were centrifuged at 3,000 $\mathrm{g}$ during 15 minutes at $4^{\circ} \mathrm{C}$ and the liquid phase was collected as inoculum. A thermal treatment $\left(90^{\circ} \mathrm{C}, 15\right.$ minutes) was applied to the inoculum to eliminate any methanogenic activity $[17,26]$. It had a $\mathrm{pH}$ of 8.95 and composed of $2.4 \%$ TS and 1.5\% VS.

\section{Acidogenesis batch tests}

Batch tests were operated in four replicates, with six different TS contents ranging from wet to dry conditions: 10, 14, $19,24,28$, and $33 \mathrm{~g}_{\mathrm{TS}} \cdot \mathrm{g}^{-1}$. In each $600 \mathrm{~mL}$ flask, the medium was composed of: $21.4 \pm 0.1 \mathrm{~g}$ of straw, $69.3 \pm 1.4 \mathrm{~mL}$ of inoculum, $16.0 \pm 0.3 \mathrm{~g}$ of 2 -( $\mathrm{N}$-morpholino) ethanesulfonic acid (MES) buffer, and $10 \mathrm{~mL}$ of a $3.2 \% \mathrm{NaOH}$ solution to maintain a pH at $5.7 \pm 0.1$ and $4.1 \pm 0.1 \mathrm{~mL}$ of a trace element solution with the following composition: 1.5 g. $\mathrm{L}^{-1}$ of $\mathrm{FeCl}_{2}, \mathrm{H}_{2} \mathrm{O} ; 62 \mathrm{mg} . \mathrm{L}^{-1}$ of $\mathrm{H}_{3} \mathrm{BO}_{3}, \mathrm{H}_{2} \mathrm{O} ; 117 \mathrm{mg} . \mathrm{L}^{-1}$ of $\mathrm{MnSO}_{4}, \mathrm{H}_{2} \mathrm{O} ; 26 \mathrm{mg} . \mathrm{L}^{-1}$ of $\mathrm{CoCl}_{2}, 6 \mathrm{H}_{2} \mathrm{O} ; 120 \mathrm{mg} \cdot \mathrm{L}^{-1}$ of $\mathrm{ZnCl}_{2} ; 28 \mathrm{mg} . \mathrm{L}^{-1}$ of $\mathrm{NiCl}_{2}, 6 \mathrm{H}_{2} \mathrm{O} ; 38 \mathrm{mg} \cdot \mathrm{L}^{-1}$ of $\mathrm{CuCl}_{2}, 2 \mathrm{H}_{2} \mathrm{O}$; $31.8 \mathrm{mg} \cdot \mathrm{L}^{-1}$ of $\mathrm{NaMoO}_{4}, 2 \mathrm{H}_{2} \mathrm{O}$; and $4.4 \mathrm{~mL}$ of $\mathrm{HCL} 37 \%$. Distillated water addition was calculated by mass balance on both TS and VS contents (including straw, inoculum, buffer, and solution addition) in order to obtain the required 
TS contents: $259.2 \pm 1.9,130.3 \pm 1.0,67.6 \pm 0.7,30.6 \pm 0.3$, $5.1 \pm 0.1$, and $0.0 \pm 0.0 \mathrm{~mL}$ for $9.5,14.2,18.8,24.0,28.1$, and $33.2 \%$ TS, respectively. The batch tests were then incubated at $35^{\circ} \mathrm{C} \pm 1$ for 11 days.

\section{Gaseous products quantification and analysis}

All batch reactors were connected to a multiplexed R3000 micro-gas chromatograph $(\mu \mathrm{GC})$ with two analytical capillary columns (SRA instrument, Marcy l'Etoile, France) to monitor gas production on line. The first column was dedicated to carbon dioxide analysis and corresponded to a $5 \AA$ molecular sieve $(10 \mathrm{~m}$ length and 0.32 $\mathrm{mm}$ diameter) with argon as carrier gas at a pressure of 30 PSI. The second column dedicated to oxygen, hydrogen, nitrogen, and methane analysis was a PLOT Q $(8 \mathrm{~m}$ length and $0.32 \mathrm{~mm}$ diameter) with helium as carrier gas (20 PSI). The injector and column temperatures were $90^{\circ} \mathrm{C}$ and $80^{\circ} \mathrm{C}$, respectively. The detector was a microthermal conductivity detector ( $\mu \mathrm{TCD})$. Multiplexing the channels allowed the simultaneous connection of 28 batch tests with a measure of the total gas production every 4 hours, by pressure measurement. To maintain a constant pressure in headspace, the gas composition was evaluated by sampling only when pressure was higher than 1.1 bars.

\section{Analytical procedure}

Reactors were sampled at the beginning (after the inoculation phase) and the end of each experiment. Samples were homogenized with a magnetic mixer (10 and 14\% TS series) or by hand-shaking (19 to 33\% TS series). In order to extract the liquid fractions of the reactors a gravimetric dilution to 5\% TS was performed. The liquid phase was then extracted after filtration with a microfiber filter GF/D $(2.7 \mu \mathrm{m}$ Whatman, Kent, UK). The $\mathrm{pH}$ was measured immediately after dilution. VFAs were measured with a gas chromatograph Varian 580 (Palo Alto, CA, USA) composed of an Elite-FFAP Crossbond Carbowax 15 $\mathrm{m}$ column connected to a flame ionization detector (FID) at $280^{\circ} \mathrm{C}$. Nitrogen at $6 \mathrm{~mL} \cdot \mathrm{min}^{-1}$ was used as carrier gas. Main fermentation metabolites were analyzed after filtration at $0.2 \mu \mathrm{m}$ by HPLC equipped with an $\mathrm{HPX}-87 \mathrm{H}$ column (Bio-Rad, Hercules, CA, USA) at $35^{\circ} \mathrm{C}$. The eluting solution corresponded to a $0.005 \mathrm{M} \mathrm{H}_{2} \mathrm{SO}_{4}$ water solution at a flow rate of $0.4 \mathrm{~mL} \cdot \mathrm{min}^{-1}$.

\section{Statistical analysis}

The $\mathrm{R}$ software (version 2.15.1) coupled with Rcmdr package version 1.8-4 was used for statistical significance measurement, using analysis of variance (ANOVA) with a $P$ value at 0.05 . The notations of significance levels of $P$ values were: ${ }^{*}<0.05 ;{ }^{* *}<0.01 ;{ }^{* * * *}<0.001$; and not significant (ns), $>0.05$.

\section{Additional files}

Additional file 1: Distribution of fermentative products for the six conditions tested. The $28 \%$ TS condition is a threshold value and is split into two groups. This table provides the original data of Figure 2.

Additional file 2: Principal component analysis (PCA) of bacterial communities was characterized using CE-SSCP profiles including discriminant peaks. Since the PCA shows an absence of correlation between profiles and TS content, butyric acid production can be attributed to a metabolic shift and not to the emergence of new population.

\section{Abbreviations}

AD: Anaerobic digestion; ANOVA: Analysis of variance; CE-SSCP: Capillary electrophoresis single strand conformation polymorphism; D: Dry fermentation; FID: Flame ionization detector; HD: Highly dry fermentation; HPLC: High performance liquid chromatography; MES: 2-(N-morpholino) ethanesulfonic acid; PCA: Principal component analysis; TS: Total solids; UASB: Upflow anaerobic sludge blanket; VFA: Volatile fatty acid; VS: Volatile solids; W: Wet fermentation; $\mu \mathrm{GC}$ : micro-gas chromatograph; $\mu \mathrm{TCD}$ : microthermal conductivity detector.

\section{Competing interests}

The authors declare that they have no competing interests.

\section{Authors' contributions}

JCM designed and carried out the experiments, analyzed results, and wrote the manuscript. ET, RE, and CD assisted and validated the experimental design and reviewed the manuscript. NB, JPD, and JPS coordinated the project and reviewed the manuscript. All authors read and approved the final manuscript.

\section{Acknowledgements}

The National Institute of Agronomic Research (INRA) finances this research. JCM was financially supported by the University of Montpellier, France.

Received: 18 June 2013 Accepted: 13 November 2013

Published: 22 November 2013

\section{References}

1. Karthikeyan O, Visvanathan C: Bio-energy recovery from high-solid organic substrates by dry anaerobic bio-conversion processes: a review. Rev Environ Sci Biotechnol 2013, 12:257-284.

2. Cioabla AE, lonel I, Dumitrel GA, Popescu F: Comparative study on factors affecting anaerobic digestion of agricultural vegetal residues. Biotechnol Biofuels 2012, 5:39.

3. De Baere L, Mattheeuws B: State of the Art of Anaerobic Digestion in Europe 32nd edition. Guadalajara: International Water Association, 12th World Congress on Anaerobic Digestion; 2010:1-7.

4. Mata-Alvarez J, Macé S, Llabrés P: Anaerobic digestion of organic solid wastes. An overview of research achievements and perspectives. Bioresour Technol 2000, 74:3-16.

5. Le Hyaric R, Benbelkacem H, Bollon J, Bayard R, Escudié R, Buffière P: Influence of moisture content on the specific methanogenic activity of dry mesophilic municipal solid waste digestate. J Chem Technol Biotechnol 2012, 87:1032-1035

6. Forster-Carneiro T, Pérez M, Romero LI: Influence of total solid and inoculum contents on performance of anaerobic reactors treating food waste. Bioresour Technol 2008, 99:6994-7002.

7. Rapport J, Zhang R, Jenkins B, Williams R: Current anaerobic digestion technologies used for treatment of municipal organic solid waste. Sacramento, CA: California Environmental Protection Agency; 2008:1-90.

8. Abbassi-Guendouz A, Brockmann D, Trably E, Dumas C, Delgenès JP, Steyer $J P$, Escudié R: Total solids content drives high solid anaerobic digestion via mass transfer limitation. Bioresour Technol 2012, 111:55-61.

9. Brown D, Shi J, Li Y: Comparison of solid-state to liquid anaerobic digestion of lignocellulosic feedstocks for biogas production. Bioresour Technol 2012, 124:379-386. 
10. Staley BF, De Los Reyes FL, Barlaz M: Effect of spatial differences in microbial activity, $\mathrm{pH}$, and substrate levels on methanogenesis initiation in refuse. App/ Environ Microbiol 2011, 77:2381-2391.

11. Li A, Chu Y, Wang X, Ren L, Yu J, Liu X, Yan J, Zhang L, Wu S, Li S: A pyrosequencing-based metagenomic study of methane-producing microbial community in solid-state biogas reactor. Biotechnol Biofuels 2013, 6:3.

12. Abbassi-Guendouz A, Trably E, Hamelin J, Dumas C, Steyer JP, Delgenès JP, Escudié R: Microbial community signature of high-solid content methanogenic ecosystems. Bioresour Technol 2013, 133:256-262.

13. Valdez-Vazquez I, Poggi-Varaldo HM: Alkalinity and high total solids affecting $\mathrm{H}_{2}$ production from organic solid waste by anaerobic consortia. Int J Hydrogen Energ 2009, 34:3639-3646.

14. Robledo-Narváez PN, Muñoz-Páez KM, Poggi-Varaldo HM, Ríos-Leal E, Calva-Calva G, Ortega-Clemente LA, Rinderknecht-Seijas N, Estrada-Vázquez C, Ponce-Noyola MT, Salazar-Montoya JA: The influence of total solids content and initial $\mathrm{pH}$ on batch biohydrogen production by solid substrate fermentation of agroindustrial wastes. J Environ Manage 2013, 128:126-137.

15. Pommier S, Chenu D, Quintard M, Lefebvre X: A logistic model for the prediction of the influence of water on the solid waste methanization in landfills. Biotechnol Bioeng 2007, 97:473-482.

16. Guo XM, Trably E, Latrille E, Carrère H, Steyer JP: Hydrogen production from agricultural waste by dark fermentation: a review. Int I Hydrogen Energ 2010, 35:10660-10673.

17. Valdez-Vazquez I, Poggi-Varaldo HM: Hydrogen production by fermentative consortia. Renew Sust Energ Rev 2009, 13:1000-1013.

18. Li J, Ban Q, Zhang L, Jha AK: Syntrophic propionate degradation in anaerobic digestion: a review. Int J Agr Biol 2012, 14:843-850.

19. Vavilin VA, Lokshina LY: Modeling of volatile fatty acids degradation kinetics and evaluation of microorganism activity. Bioresour Technol 1996, 57:69-80.

20. Wang Q, Kuninobu M, Ogawa HI, Kato Y: Degradation of volatile fatty acids in highly efficient anaerobic digestion. Biomass Bioenerg 1999, 16:407-416

21. Cui Z, Shi J, Li Y: Solid-state anaerobic digestion of spent wheat straw from horse stall. Bioresour Technol 2011, 102:9432-9437.

22. Cord-Ruwisch R, Seitz H, Conrad R: The capacity of hydrogenotrophic anaerobic bacteria to compete for traces of hydrogen depends on the redox potential of the terminal electron acceptor. Arch Microbio/ 1988, 1:350-357.

23. Stadtman E, Stadtman T, Barker H: Tracer experiments on the mechanism of synthesis of valeric and caproic acids by Clostridium kluyveri. J Biol Chem 1949, 178:677-682.

24. Orzua MC, Mussatto SI, Contreras-Esquivel JC, Rodriguez R, De la Garza H, Teixeira J, Aguilar CN: Exploitation of agro industrial wastes as immobilization carrier for solid-state fermentation. Ind Crop Prod 2009, 30:24-27.

25. Monlau F, Sambusiti C, Barakat A, Guo XM, Latrille E, Trably E, Steyer JP, Carrere H: Predictive models of biohydrogen and biomethane production based on the compositional and structural features of lignocellulosic materials. Environ Sci Technol 2012, 46:12217-12225.

26. Quéméneur M, Bittel $M$, Trably E, Dumas $C$, Fourage $L$, Ravot $G$, Steyer JP, Carrère $\mathrm{H}$ : Effect of enzyme addition on fermentative hydrogen production from wheat straw. Int J Hydrogen Energ 2012, 37:10639-10647.

27. Nasirian N, Almassi M, Minaei S, Widmann R: Development of a method for biohydrogen production from wheat straw by dark fermentation. Int J Hydrogen Energ 2011, 36:411-420.

28. Fang $\mathrm{H}$, Li C, Zhang T: Acidophilic biohydrogen production from rice slurry. Int J Hydrogen Energ 2006, 31:683-692.

29. Frigon J, Guiot SR: Biomethane production from starch and lignocellulosic crops: a comparative review. Biofuel Bioprod Bior 2010, 4:447-458.

30. Valdez-Vazquez I, Rios-Leal E, Esparaza-Garcia F, Cecchi F, Poggi-Varaldo H: Semi-continuous solid substrate anaerobic reactors for $\mathrm{H}_{2}$ production from organic waste: mesophilic versus thermophilic regime. Int J Hydrogen Energ 2005, 30:1383-1391.

31. Van Ginkel S, Logan BE: Inhibition of biohydrogen production by undissociated acetic and butyric acids. Environ Sci Technol 2005 39:9351-9356.

32. Martin D: The site of reaction in solid-state digestion. Process Saf Environ Protect 2001, 79:29-37.
33. Michel-Savin D, Marchal R, Vandecasteele JP: Control of the selectivity of butyric acid production and improvement of fermentation performance with Clostridium tyrobutyricum. Appl Microbiol Biotechno/ 1990, 32:387-392.

34. Olofsson K, Bertilsson M, Lidén G: A short review on SSF - an interesting process option for ethanol production from lignocellulosic feedstocks. Biotechnol Biofuels 2008, 1:7.

35. García-Bernet D, Buffière $P$, Latrille E, Steyer JP, Escudié R: Water distribution in biowastes and digestates of dry anaerobic digestion technology. Chem Eng J 2011, 172:924-928.

doi:10.1186/1754-6834-6-164

Cite this article as: Motte et al:: Total solids content: a key parameter of metabolic pathways in dry anaerobic digestion. Biotechnology for Biofuels 2013 6:164

\section{Submit your next manuscript to BioMed Central and take full advantage of:}

- Convenient online submission

- Thorough peer review

- No space constraints or color figure charges

- Immediate publication on acceptance

- Inclusion in PubMed, CAS, Scopus and Google Scholar

- Research which is freely available for redistribution

Submit your manuscript at www.biomedcentral.com/submit
C Biomed Central 